\title{
Association Between High Neutrophil to Lymphocyte Ratio and Delayed Recovery From Bell's Palsy
}

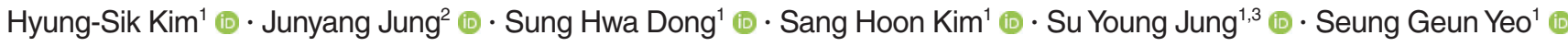 \\ ${ }^{I}$ Department of Otolaryngology-Head and Neck Surgery, Graduate School, Kyung Hee University, Seoul; \\ ${ }^{2}$ Department of Anatomy and Neurobiology, School of Medicine, Kyung Hee University, Seoul; \\ ${ }^{3}$ Department of Otorhinolaryngology-Head and Neck Surgery, Myongji Hospital, Hanyang University Medical Center, Goyang, Korea
}

Objectives. Factors predictive of the severity of and recovery from Bell's palsy remain unclear. This study evaluated the association between neutrophil to lymphocyte ratio (NLR) and the severity of and recovery from Bell's palsy.

Methods. This retrospective study included 51 patients who were hospitalized with Bell's palsy from 2015 to 2017. Degree of paralysis was assessed by House-Brackmann (H-B) grade. Patients with H-B grades 2-4 were classified as having mild to moderate palsy and patients with H-B grade 5 or 6 were classified as having severe palsy. Patients were evaluated for obesity, hypertension and diabetes mellitus, and blood tests were performed to determine NLR and platelet to lymphocyte ratio. Patients were treated with steroids and antiviral agents. H-B grade was assessed 1 week, 1 month, and 3 months after treatment.

Results. NLR was significantly higher in patients with severe than with mild to moderate palsy $(P=0.048)$. Recovery time was significantly longer in patients with high NLR than low NLR $(P=0.045)$.

Conclusion. Higher NLR in patients with Bell's palsy was associated with longer recovery time. NLR may be prognostic of recovery time in patients with Bell's palsy.

Keywords. Neutrophils; Lymphocytes; Bell Palsy; Facial Paralysis

\section{INTRODUCTION}

The annual prevalence of Bell's palsy in the general population has been reported to range from 11.5 to 40.2 per 100,000 persons [1].Viral inflammation and immune mechanisms are thought to play a major role in the pathogenesis of Bell's palsy [2], in as much as herpes simplex virus- 1 has been detected in the endoneurial fluid of facial nerves in Bell's palsy patients [3], and recent studies have suggested that the neutrophil to lymphocyte

\footnotetext{
- Received June 28, 2018

Revised September 18, 2018

Accepted October 18, 2018

- Corresponding author: Seung Geun Yeo

Department of Otolaryngology-Head and Neck Surgery, Kyung Hee

University Medical Center, 23 Kyungheedae-ro, Dongdaemun-gu,

Seoul 02447, Korea

Tel: +82-2-958-8474, Fax: +82-2-958-8470

E-mail: yeo2park@gmail.com
}

ratio (NLR) is higher in patients with than without Bell's palsy [4-6]. NLR is regarded as a marker of inflammation, as well as being used to assess the risk of cardiovascular disease and the prognosis of patients with cardiovascular disease and with several types of cancer [7-10].

Electroneuronography (ENoG) was the first tool used to predict the prognosis of patients with Bell's palsy in the early 1970s [11]. Other prognostic methods include electromyography (EMG), nerve excitability test, maximal stimulation test, blink reflex test, and vestibular evoked myogenic potential. However, ENoG and EMG, the primary methods used in clinical practice, have several disadvantages. Guidelines recommend that ENoG and EMG be performed after 3 and 14 days of facial paralysis, respectively [12]. In addition, no currently known method can predict recovery time in patients with Bell's palsy [13]. This study therefore evaluated the associations between NLR and the severity of and recovery time from Bell's palsy.

Copyright (C) 2019 by Korean Society of Otorhinolaryngology-Head and Neck Surgery.

This is an open-access article distributed under the terms of the Creative Commons Attribution Non-Commercial License (http://creativecommons.org/licenses/by-nc/4.0)

which permits unrestricted non-commercial use, distribution, and reproduction in any medium, provided the original work is properly cited. 


\section{MATERIALS AND METHODS}

\section{Study population}

This retrospective study included patients in Kyung Hee Medical Center who were diagnosed with Bell's palsy from 2015 to 2017. All patients underwent physical examination by an ENT specialist, with the severity of Bell's palsy assessed by House-Brackmann (H-B) grade. Body mass index (BMI) was calculated from each patient's height and weight. Complete blood count, differential count, and glycated hemoglobin (HbA1c) concentration were also measured. Patients with traumatic facial palsy, facial palsy of central origin, recurrent facial palsy, Ramsay-Hunt syndrome, or a previous history of otologic surgery were excluded, as were patients who first presented $\geq 5$ days after facial paralysis first occurred, and patients with hematologic disease. Patient information was anonymized, and the study protocol was approved by the Institutional Review Board of Kyung Hee Medical Center (IRB No. 2017-01-009). As this was a retrospective study, no informed consent was required.

\section{Treatment process}

All patients were treated with steroids and the antiviral agent famciclovir. The steroid treatment schedule consisted of $80 \mathrm{mg} /$ day for 4 days, $60 \mathrm{mg} /$ day for 2 days, $40 \mathrm{mg} /$ day for 2 days, 20 $\mathrm{mg} /$ day for 2 days, and $10 \mathrm{mg} /$ day for 2 days. Patients were also treated with $750 \mathrm{mg}$ /day famciclovir for 7 days. Patients were hospitalized for about 7 days and subsequently visited the outpatient clinic 1 week and 1, 3, and 6 months after discharge. All patients underwent ENoG 5 days after facial paralysis first occurred. The severity of facial paralysis, as determined by H-B grade, was assessed by the same otolaryngologist at every outpatient visit, with $\mathrm{H}-\mathrm{B}$ grades $\leq 2$ defined as favorable outcomes.

\section{Blood tests}

Blood samples were obtained on the day of admission, within 5 days after the onset of facial paralysis. Platelet, lymphocyte, and neutrophil counts were measured, with the platelet to lymphocyte ratio defined as the platelet count divided by the absolute lymphocyte count, and the NLR as the absolute neutrophil count divided by the absolute lymphocyte count. The upper limit of NLR for healthy adults was set to 3.53 based on previous findings [14].

\section{H I G H L I G H T S}

- Higher neutrophil to lymphocyte ratio in patients with Bell's palsy was associated with longer recovery time.

- The neutrophil to lymphocyte ratio may be prognostic of recovery time in patients with Bell's palsy.

\section{Obesity}

The World Health Organization standards for Asia-Pacific subjects define persons with BMI $<18.5 \mathrm{~kg} / \mathrm{m}^{2}$ as underweight, $\geq 18.5 \mathrm{~kg} / \mathrm{m}^{2}$ and $<23 \mathrm{~kg} / \mathrm{m}^{2}$ as normal weight, $\geq 23 \mathrm{~kg} / \mathrm{m}^{2}$ and $<25 \mathrm{~kg} / \mathrm{m}^{2}$ as overweight, $\geq 25 \mathrm{~kg} / \mathrm{m}^{2}$ and $<30 \mathrm{~kg} / \mathrm{m}^{2}$ as obese, and $\geq 30 \mathrm{~kg} / \mathrm{m}^{2}$ as severely obese, respectively [15]. In this study, obesity was defined as a BMI $\geq 25 \mathrm{~kg} / \mathrm{m}^{2}$ and normal weight as a BMI $<25 \mathrm{~kg} / \mathrm{m}^{2}$.

\section{Severity of initial facial paralysis}

H-B grade 2 was defined as mild facial paralysis, H-B grades 3 and 4 as moderate facial paralysis, and H-B grades 5 and 6 as severe facial paralysis [16]. Patients were classified into two groups, those with mild to moderate facial paralysis (H-B grades 2-4) and severe facial paralysis (H-B grade 5 or 6).

\section{Recovery time}

Recovery time was defined as the duration from the day facial paralysis first occurred until the day that facial paralysis had improved to H-B grade $\leq 2$.

Table 1. Baseline demographics and clinical characteristics of patients with Bell's palsya)

\begin{tabular}{lc}
\hline Variable & Value \\
\hline No. of patients & 51 \\
\hline Male:female & $16: 35$ \\
Age (yr) & $39.7 \pm 20.1$ \\
Recovery time (day) $)^{\text {b) }}$ & $48.9 \pm 35.9$ \\
Initial severity (H-B grade) & $3.8 \pm 0.9$ \\
BMl (kg/m ${ }^{2}$ ) & $23.2 \pm 4.2$ \\
Underlying disease & \\
Obesity:non-obesity & $16: 35$ \\
\hline HTN:non-HTN & $11: 40$ \\
DM:non-DM & $7: 44$ \\
Blood laboratory test & \\
Neutrophil (\%) & $65.9 \pm 14.4$ \\
Lymphocyte (\%) & $26.1 \pm 11.1$ \\
Monocyte (\%) & $4.5 \pm 2.0$ \\
Eosinophil (\%) & $1.7 \pm 1.7$ \\
Basophil (\%) & $0.4 \pm 0.3$ \\
\hline NLR & $3.8 \pm 3.7$ \\
PLR & $171.3 \pm 116.9$ \\
\hline Platelet count (/mL) & $284,588.2 \pm 91,036.5$ \\
WBC count (/mL) & $8,501.6 \pm 3,016.1$ \\
HbA1c (\%) & $5.7 \pm 0.7$ \\
Electrodiagnostic test & \\
ENoG 5 days after onset (\%) & $50.8 \pm 21.9$ \\
\hline
\end{tabular}

Values are presented as mean \pm standard deviation.

$\mathrm{H}-\mathrm{B}$ grade, House-Brackmann grade; BMI, body mass index; HTN, hypertension; DM, diabetes mellitus; NLR, neutrophil lymphocyte ratio (absolute neutrophil count/absolute lymphocyte count); PLR, platelet to lymphocyte ratio (platelet count/absolute lymphocyte count); WBC, white blood cell; HbA1c, glycated hemoglobin; ENoG, electroneuronography.

a) Mild palsy, $\mathrm{H}-\mathrm{B}$ grade 2; moderate palsy, $\mathrm{H}-\mathrm{B}$ grade 3, 4; severe palsy,

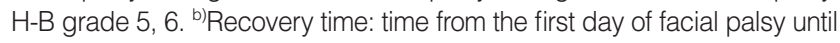
the day it improved to $\mathrm{H}-\mathrm{B}$ grade 1 or 2 . 


\section{Statistical analysis}

All statistical analyses were performed using IBM SPSS ver. 20.0 (IBM Corp., Armonk, NY, USA), with $P<0.05$ defined as statistically significant. Data are expressed as mean \pm standard deviation or as frequency and percentage. Normality was assessed using the Shapiro-WilkW-test. Categorical variables were compared using the chi-square test, and continuous variables were compared using Student $t$-test, Mann-Whitney $U$-test, as appropriate. All calculations included determination of $95 \%$ confidence intervals to estimate the effect size and mean differences.

\section{RESULTS}

This study included a total of 51 patients, 16 males and 35 females, of age $39.7 \pm 20.1$ years. Their mean severity of initial facial paralysis was $\mathrm{H}-\mathrm{B}$ grade $3.8 \pm 0.9$, and their mean BMI was $23.2 \pm 4.2 \mathrm{~kg} / \mathrm{m}^{2}$, with 16 patients being obese and 35 of normal

Table 2. Baseline demographics and clinical characteristics of patients with mild to moderate and severe Bell's palsya)

\begin{tabular}{lccc}
\hline Variable & $\begin{array}{c}\text { Mild to moderate } \\
\text { palsy }\end{array}$ & Severe palsy & P-value \\
\hline No. of patients & 39 & 12 & \\
Male:female & $10: 29$ & $6: 6$ & 0.157 \\
Age (yr) & $38.6 \pm 19.5$ & $43.3 \pm 22.2$ & 0.571 \\
Recovery time (day) $)^{b}$ & $39.1 \pm 28.9$ & $78.6 \pm 41.3$ & $0.002^{\star}$ \\
BMl (kg/m²) & $22.6 \pm 3.4$ & $25.1 \pm 5.9$ & 0.069 \\
Underlying disease & & & \\
Obesity:non-obesity & $9: 30$ & $7: 5$ & $0.033^{*}$ \\
HTN:non-HTN & $9: 30$ & $2: 10$ & 1.000 \\
DM:non-DM & $4: 35$ & $3: 9$ & 0.334 \\
Blood laboratory test & & & \\
Neutrophil (\%) & $63.8 \pm 14.4$ & $72.9 \pm 12.4$ & 0.053 \\
Lymphocyte (\%) & $27.8 \pm 11.1$ & $20.5 \pm 9.6$ & $0.048^{*}$ \\
Monocyte (\%) & $4.6 \pm 2.1$ & $4.1 \pm 1.9$ & 0.506 \\
Eosinophil (\%) & $1.9 \pm 1.8$ & $1.0 \pm 0.9$ & 0.098 \\
Basophil (\%) & $0.5 \pm 0.3$ & $0.3 \pm 0.2$ & 0.112 \\
NLR & $3.5 \pm 3.8$ & $4.8 \pm 3.2$ & $0.048^{*}$ \\
PLR & $143.2 \pm 100.4$ & $195.9 \pm 160.0$ & 0.807 \\
Platelet count (/mL) & $278,410.3 \pm$ & $304,666.7 \pm$ & 0.973 \\
WBC count (/mL) & $73,129.6$ & $136,460.0$ & \\
HbA1c (\%) & $7,912.6 \pm 2,627.5$ & $10,415.8 \pm 3,503.4$ & $0.021^{*}$ \\
Electrodiagnostic test & $5.7 \pm 0.7$ & $5.9 \pm 0.7$ & 0.154 \\
ENoG (\%) & $54.1 \pm 18.8$ & $33.6 \pm 23.3$ & $0.010^{*}$ \\
\hline & & &
\end{tabular}

Values are presented as mean \pm standard deviation.

BMI, body mass index; HTN, hypertension; DM, diabetes mellitus; NLR, neutrophil to lymphocyte ratio (absolute neutrophil count/absolute lymphocyte count); PLR, platelet to lymphocyte ratio (platelet count/absolute lymphocyte count); WBC, white blood cell; HbA1c, glycated hemoglobin; ENoG, electroneuronography; H-B grade, House-Brackmann grade.

${ }^{a}$ Mild palsy, $\mathrm{H}-\mathrm{B}$ grade 2; moderate palsy, $\mathrm{H}-\mathrm{B}$ grade 3, 4; severe palsy,

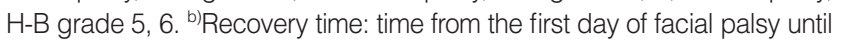
the day it improved to $\mathrm{H}-\mathrm{B}$ grade 1 or 2 .

${ }^{\star} P<0.05$. weight (Table 1).

Classification of these 51 patients by severity of initial facial paralysis showed that $39(76.5 \%)$ had mild to moderate palsy (H-B grades 2-4) and 12 (23.5\%) had severe palsy (H-B grades $5-6)$. These two groups differed significantly in mean recovery time (39.1 \pm 28.9 days vs. $78.6 \pm 41.3$ days, $P=0.002)$, mean lymphocyte percentage $(27.8 \% \pm 11.1 \%$ vs. $20.5 \% \pm 9.6 \%, P=$ $0.048)$, mean NLR ( $3.5 \pm 3.8$ vs. $4.8 \pm 3.2, P=0.048)$, mean white blood cell (WBC) count $(7,912.6 \pm 2,627.5 / \mathrm{mL}$ vs. $10,415.3 \pm$ $3,503.4 / \mathrm{mL}, P=0.021)$, mean ENoG score $(56.1 \% \pm 18.8 \%$ vs. $33.6 \% \pm 23.3 \%, P=0.010$ ), and the percentage of obese patients (23.1\% [9/39] vs. $41.7 \%$ [5/12], $P=0.033)$. In contrast, there were no between-group differences in mean age $(38.6 \pm 19.5$ years vs. $43.3 \pm 22.2$ years, $P=0.571$ ) and mean HbA1c concentration $(5.7 \% \pm 0.7 \%$ vs. $5.9 \% \pm 0.7 \%, P=0.154)$. The percentages of patients with diabetes mellitus $(10.3 \%$ [4/39] vs. $25 \%$ [3/12], $P=0.334)$ and hypertension $(23.1 \%$ [9/39] vs. $16.7 \%$ [2/12], $P=1.000$ ) also did not differ significantly (Table 2).

In analyzing the significance of factors related to recovery time from facial paralysis, we found that mean recovery times did not differ significantly between patients with and without hypertension ( $42.9 \pm 28.7$ days vs. $50.6 \pm 37.8$ days, $P=0.963$ ), with and without diabetes mellitus $(71.4 \pm 40.4$ days vs. $45.3 \pm 34.3$ days, $P=0.117)$, and with normal weight and obesity $(44.1 \pm 36.3$ days vs. $59.5 \pm 33.8$ days, $P=0.059$ ). However, mean recovery time was significantly longer in patients with high NLR than normal NLR (66.8 \pm 11.2 days vs. $40.7 \pm 4.8$ days, $P=0.045$ ) (Fig. 1 ). In evaluating factors associated with the severity of initial facial paralysis, we found that mean H-B grades did not differ signifi-

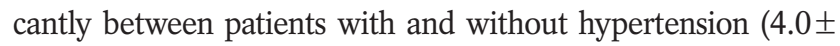
0.6 vs. $3.8 \pm 1.0, P=0.592$ ), with and without diabetes mellitus (4.4 \pm 0.5 vs. $3.8 \pm 0.9, P=0.068$ ), and with normal and high NLR ( $3.7 \pm 0.2$ vs. $4.1 \pm 0.2, P=0.098$ ). In contrast, mean $\mathrm{H}-\mathrm{B}$ grades differed significantly between normal weight and obese patients (3.6 \pm 0.9 vs. $4.3 \pm 0.7, P=0.010$ ) (Fig. 2).

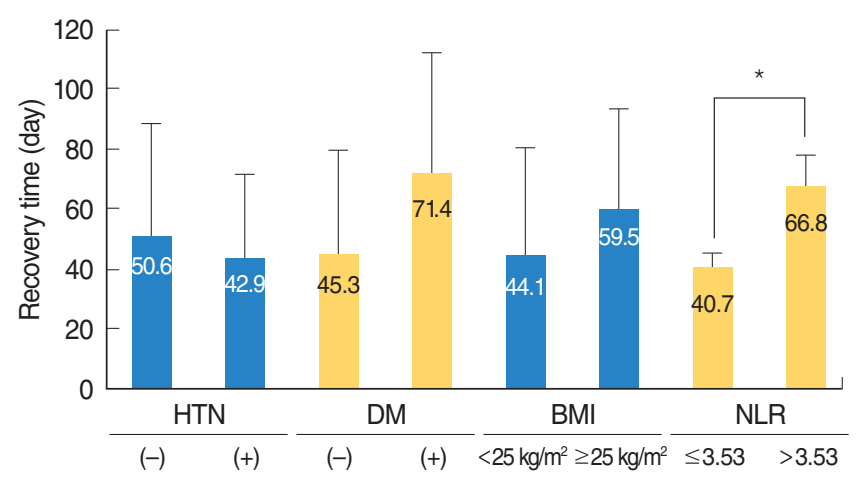

Fig. 1. Relationships between hypertension (HTN), diabetes mellitus (DM), body mass index (BMI), and neutrophil to lymphocyte ratio (NLR) and recovery time in patients with Bell's palsy. Normal weight, BMl $<25 \mathrm{~kg} / \mathrm{m}^{2}$; obesity, BMl $\geq 25 \mathrm{~kg} / \mathrm{m}^{2}$ and normal $\mathrm{NLR}$, $\leq 3.53$; high NLR, $>3.53 .{ }^{*} P<0.05$. 


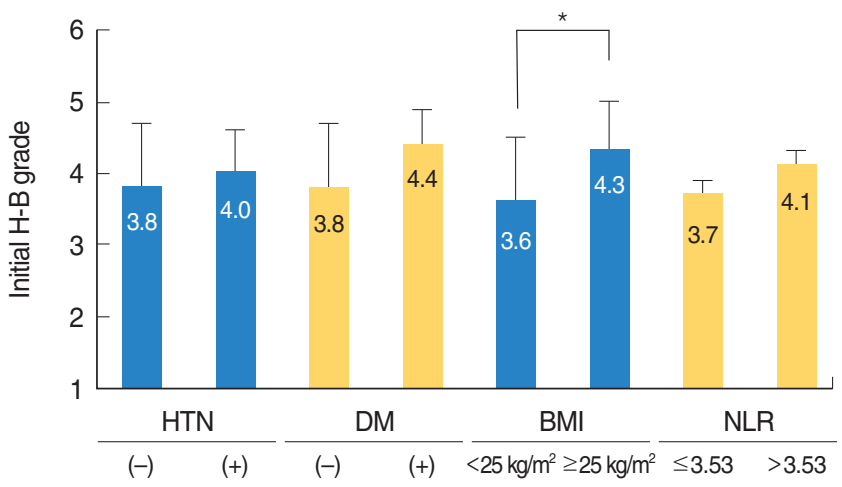

Fig. 2. Relationships between hypertension (HTN), diabetes mellitus (DM), body mass index (BMI), and neutrophil to lymphocyte ratio (NLR) and initial severity in patients with Bell's palsy. $\mathrm{H}$-B grade, House-Brackmann grade; normal weight, $\mathrm{BMl}<25 \mathrm{~kg} / \mathrm{m}^{2}$; obesity, $\mathrm{BMl} \geq 25 \mathrm{~kg} / \mathrm{m}^{2}$; normal NLR, $\leq 3.53$; high NLR, $>3.53$. ${ }^{*} P<0.05$.

\section{DISCUSSION}

Many studies have evaluated prognostic factors in Bell's palsy patients. Among the factors associated with the prognosis of patients with Bell's palsy are patient age, severity (i.e., initial H-B grade), time from initial symptoms to the start of recovery, time from initial symptoms to the start of corticosteroid treatment, pain, dyslipidemia, diabetes, hypertension and body weight.

ENoG and EMG remain the tools most frequently used to predict prognosis in patients with Bell's palsy, and stapedial reflex tests may also be useful. These methods, however, have some disadvantages. ENoG should be performed after 3 days of facial paralysis; EMG can first assess pathological spontaneous activity 2 weeks after facial paralysis first occurs, and the accuracy of stapedial reflex tests can be reduced by a middle ear lesion on the ipsilateral side of the paralysis, or if the facial nerve lesion is far from the branch of the nerve that involves the stapedius muscle [17].

Although these methods can predict recovery time in patients with Bell's palsy, they are not very reliable. This study evaluated whether a parameter determined using a simple blood test, the NLR, could predict recovery time. NLR is an indicator of cellmediated immunodeficiencies associated with systemic inflammation, and can therefore be considered a marker of the inflammatory state of a patient.

The pathophysiology of Bell's palsy may include viral infection, ischemic neuropathy, and autoimmune responses $[2,18,19]$, with a viral inflammatory/immune mechanism thought to play a major role in the pathogenesis of Bell's palsy [2]. Inflammatory changes resulting from viral infection may result in swelling of the facial nerve, compressing the nerve and resulting in facial nerve paralysis. Increased pressure on the nerve prevents vein reflux, with congestion of the blood vessels leading to a vicious cycle of edema, compression, and ischemia of the facial nerve, a cycle considered an important factor related to poor prognosis in patients with facial paralysis [20,21].

Immune system cells, including lymphocytes, neutrophils, and monocytes, as well as cell-mediated inflammatory responses, are recognized as important in tumorigenesis and carcinogenesis [22]. NLR has therefore been evaluated as a prognostic factor in patients with head and neck, pancreatic, and ovarian cancer. Relative to normal NLR, elevated NLR had a hazard ratio (HR) for survival in all patients with head and neck cancer of 1.78, including HRs in patients with cancers of the oral cavity, nasopharynx, larynx, and hypopharynx of 1.56, 1.66, 1.55, and 2.36, respectively [10]. In patients with ovarian cancer, elevated NLR had an HR of 1.63 [9]. In addition, the overall survival rate of patients with metastatic pancreatic cancer was significantly lower when NLR was >3.75 [8]. Because the development of Bell's palsy has been associated with an inflammatory mechanism, NLR may be predictive of outcomes in patients with this condition, with studies suggesting that NLR is higher in patients with Bell's palsy than in normal subjects [5,22]. Furthermore, high NLR was found to be associated with poor prognosis in patients with Bell's palsy [23]. We found that NLR differed significantly between groups of patients with mild to moderate and severe facial paralysis. Although the severity of initial facial paralysis did not differ significantly between groups of patients with normal and high NLR $(P=0.098)$, their mean H-B grades were $3.7 \pm 0.2$ and $4.1 \pm 0.2$, respectively. The finding that $H-B$ grade was generally high in patients with high NLR suggested a correlation between the severity of facial paralysis and NLR. In contrast, the upper limit of NLR had not been clearly defined until recently, with various studies differing in the upper limit of NLR. Because a study in 413 healthy adults found that the mean NLR was 1.65 and the upper limit was 3.53 [14], our study set the upper limit of NLR at 3.53.

We also found that the time to recovery from facial palsy was significantly longer in the high than in the normal NLR group. Similar to other peripheral nerves, the facial nerve was found to have a series of planned changes for recovery following injury. Nerve injury induces inflammation, causing WBCs to aggregate at the site of injury. Cells of the innate immune system aggregate within a few hours to several days after injury. Neutrophils contain toxic substances that interfere with the growth of bacteria and fungi, kill these microorganisms, and reach the infected area the fastest. In animals, neutrophils present at the site of neuronal damage were found to affect pain sensitivity, but not peripheral nerve regeneration [24], although the effects of neutrophils and lymphocytes on axon regeneration have yet to be clarified [25].

Studies have shown the relationship between obesity and inflammation. For example, systemic low grade chronic inflammation has been observed in obese patients [26]. Because inflammation and immune mechanisms play important roles in the development of Bell's palsy, our results suggest that obesity-associated low grade chronic inflammation may worsen the degree of 
paralysis in obese patients with Bell's palsy. In addition, obesity has been associated with other chronic diseases, suggesting that the degree of paralysis may be worsened by these comorbid diseases.

This study also found that WBC counts were significantly higher in the severe than in the mild to moderate palsy group. WBC counts are significantly higher in patients with Bell's palsy than in normal individuals, suggesting that inflammation is involved in the development of Bell's palsy [27].

We performed multivariate binary logistic regression analysis, using BMI, hypertension (HTN), diabetes mellitus (DM), and NLR as independent variables and recovery time as the dependent variable. The variance inflation factors of these independent variables were low $(1.035,1.169,1.138$, and 1.009 , respectively) and did not show multicollinearity. Their regression coefficients were $1.515,-17.597,32.420$, and 2.510, respectively, but only DM was statistically significant $(P=0.031)$. BMI $(P=0.196)$ and HTN $(P=0.162)$ were not statistically significant, whereas NLR tended toward significance $(P=0.057)$. These results suggested that these factors may be statistically significant in studies on larger numbers of patients. Although the results of our multivariate analysis suggested that DM-associated deterioration in blood circulation may have an adverse effect on the prognosis of patients with facial palsy, recent studies on diabetes and recovery time from facial paralysis have reported that diabetes does not affect the prognosis of patients with Bell's palsy [28]. Thus, it remains unclear whether DM affects the prognosis of patients with Bell's palsy.

This study had several limitations. First, the time from the onset of paralysis to blood sampling was not constant. Second, because the relationships of neutrophils and lymphocytes with axon regeneration have not yet been clarified, the results of this study cannot explain the pathophysiology of Bell's palsy. Third, it is difficult to determine the exact recovery time by assessments at regular outpatient visits. Fourth, the number of subjects was relatively small, preventing sub-analyses. Fifth, we could not compare NLRs before and after treatment and before and after recovery. Sixth, we did not measure inflammatory markers (e.g., erythrocyte sedimentation rate or C-reactive protein concentration) other than WBC count due to the retrospective design of this study. The time to recovery from facial palsy was significantly longer in patients with high NLR than low NLR. NLR may therefore be a useful marker for predicting recovery time in patients with Bell's palsy.

\section{CONFLICT OF INTEREST}

No potential conflict of interest relevant to this article was reported.

\section{ORCID}

Hyung-Sik Kim https://orcid.org/0000-0001-7475-1622

Jungyang Jung https://orcid.org/0000-0003-3946-5406

Sung Hwa Dong https://orcid.org/0000-0002-7633-8353

Sang Hoon Kim https://orcid.org/0000-0001-5045-5060

SuYoung Jung https://orcid.org/0000-0001-6398-1297

Seung Geun Yeo https://orcid.org/0000-0001-8021-1024

\section{AUTHOR CONTRIBUTIONS}

Conceptualization: SGY. Data curation: HSK, SYJ, SHK. Formal analysis: SYJ, SHK. Funding acquisition: SGY. Methodology: HSK, SHD, SYJ, SHK. Project administration: JJ, SGY.Visualization: SGY.Writing - original draft: HSK, SGY.Writing - review \& editing: all authors.

\section{REFERENCES}

1. De Diego JI, Prim MP, Madero R, Gavilan J. Seasonal patterns of idiopathic facial paralysis: a 16-year study. Otolaryngol Head Neck Surg. 1999 Feb;120(2):269-71.

2. Adour KK, Bell DN, Hilsinger RL Jr. Herpes simplex virus in idiopathic facial paralysis (Bell palsy). JAMA. 1975 Aug;233(6):527-30.

3. Murakami S, Mizobuchi M, NakashiroY, DoiT, Hato N, Yanagihara N. Bell palsy and herpes simplex virus: identification of viral DNA in endoneurial fluid and muscle. Ann Intern Med. 1996 Jan;124(1 Pt 1):27-30.

4. Atan D, Ikinciogullari A, Koseoglu S, Ozcan KM, Cetin MA, Ensari S, et al. New predictive parameters of bell's palsy: neutrophil to lymphocyte ratio and platelet to lymphocyte ratio. Balkan Med J. 2015 Apr;32(2):167-70.

5. Sahin C, Varim C. Neutrophil to lymphocyte ratio, platelet to lymphocyte ratio, mean platelet volume and red cell distribution width measures in bells palsy. Open Access Maced J Med Sci. 2017 Mar; 5(1):14-8.

6. Ozler GS, Gunak G. Neutrophil-lymphocyte ratio: a new predictive and prognostic factor in patients with Bell palsy. J Craniofac Surg. 2014 May;25(3):944-5.

7. Xu N,Tang XF, Yao Y, Zhao X, Chen J, Gao Z, et al. Predictive value of neutrophil to lymphocyte ratio in long-term outcomes of left main and/or three-vessel disease in patients with acute myocardial infarction. Catheter Cardiovasc Interv. 2018 Feb;91(S1):551-7.

8. Song JY, Chen MQ, Guo JH, Lian SF, Xu BH. Combined pretreatment serum CA19-9 and neutrophil-to-lymphocyte ratio as a potential prognostic factor in metastatic pancreatic cancer patients. Medicine (Baltimore). 2018 Jan;97(4):e9707.

9. Huang QT, Zhou L, Zeng WJ, Ma QQ,Wang W, Zhong M, et al. Prognostic significance of neutrophil-to-lymphocyte ratio in ovarian cancer: a systematic review and meta-analysis of observational studies. Cell Physiol Biochem. 2017 Jun;41(6):2411-8.

10. Mascarella MA, Mannard E, Silva SD, Zeitouni A. Neutrophil-tolymphocyte ratio in head and neck cancer prognosis: a systematic review and meta-analysis. Head Neck. 2018 May;40(5):1091-100.

11. Miehlke A. Surgery of the facial nerve. 2nd ed. Philadelphia (PA): W.B. Saunders; 1973.

12. Mannarelli G, Griffin GR, Kileny P, Edwards B. Electrophysiological 
measures in facial paresis and paralysis. OperTech Otolayngol Head Neck Surg. 2012 Dec;23(4):236-47.

13. Baugh RF, Basura GJ, Ishii LE, Schwartz SR, Drumheller CM, Burkholder R, et al. Clinical practice guideline: Bell's palsy. Otolaryngol Head Neck Surg. 2013 Nov;149(3 Suppl):S1-27.

14. Forget P, Khalifa C, Defour JP, Latinne D, Van Pel MC, De Kock M What is the normal value of the neutrophil-to-lymphocyte ratio? BMC Res Notes. 2017 Jan;10(1):12.

15. World Health Organization. The Asia-Pacific perspective: redefining obesity and its treatment. Sydney: Health Communications Australia; 2000.

16. Choi SA, Shim HS, Jung JY, Kim HJ, Kim SH, Byun JY, et al. Association between recovery from Bell's palsy and body mass index. Clin Otolaryngol. 2017 Jun;42(3):687-92.

17. Volk GF, Klingner C, Finkensieper M,Witte OW, Guntinas-Lichius O, Prognostication of recovery time after acute peripheral facial palsy: a prospective cohort study. BMJ Open. 2013 Jun;3(6):e003007.

18. Hilger JA. The nature of Bell's palsy. Laryngoscope. 1949 Mar;59(3): 228-35.

19. Abramsky O, Webb C, Teitelbaum D, Arnon R. Cellular immune response to peripheral nerve basic protein in idiopathic facial paralysis (Bell's palsy). J Neurol Sci. 1975 Sep;26(1):13-20.

20. Townsend JJ, Collins PK. Peripheral nervous system demyelination with herpes simplex virus. J Neuropathol Exp Neurol. 1986 Jul; 45(4):419-25.
21. Fisch U, Esslen E. Total intratemporal exposure of the facial nerve: pathologic findings in Bell's palsy. Arch Otolaryngol. 1972 Apr;95(4): 335-41.

22. Kilickaya MM, Tuz M, Yariktas M, Yasan H, Aynali G, Bagci O. The importance of the neutrophil-lymphocyte ratio in patients with idiopathic peripheral facial palsy. Int J Otolaryngol. 2015;2015:981950.

23. Bucak A, Ulu S, Oruc S, Yucedag F, Tekin MS, Karakaya F, et al. Neutrophil-to-lymphocyte ratio as a novel-potential marker for predicting prognosis of Bell palsy. Laryngoscope. 2014 Jul;124(7):1678-81.

24. Nadeau S, Filali M, Zhang J, Kerr BJ, Rivest S, Soulet D, et al. Functional recovery after peripheral nerve injury is dependent on the pro-inflammatory cytokines IL-1 $\beta$ and TNF: implications for neuropathic pain. J Neurosci. 2011 Aug;31(35):12533-42.

25. Benowitz LI, Popovich PG. Inflammation and axon regeneration. Curr Opin Neurol. 2011 Dec;24(6):577-83.

26. Monteiro R, Azevedo I. Chronic inflammation in obesity and the metabolic syndrome. Mediators Inflamm. 2010;2010:289645.

27. Kum RO, Yurtsever Kum N, Ozcan M, Yilmaz YF, Gungor V, Unal A, et al. Elevated neutrophil-to-lymphocyte ratio in Bell's palsy and its correlation with facial nerve enhancement on MRI. Otolaryngol Head Neck Surg. 2015 Jan;152(1):130-5.

28. Sevik Elicora S, Erdem D. Does type 2 diabetes mellitus affect the healing of Bell's palsy in adults? Can J Diabetes. 2018 Aug;42(4): 433-6. 